\title{
BI0-FLASH® Providing Early Diagnosis of Autoimmune Diseases
}

\author{
By Christine Foran
}

In 2012, Dr. Marvin Fritzler, MD, Professor at the Cumming School of Medicine and Director of Mitogen International acquired for the University of Calgary, the BIO-FLASH ${ }^{\circledR}-\mathrm{a}$ new machine for diagnosing autoimmune diseases. Not only new to Calgary, the BIO-FLASH ${ }^{\circledR}$ was the first of its kind in North America. Currently there are still only 60 machines worldwide, with the University of Calgary now owning two.

There are over 80 types of autoimmune diseases (1) affecting approximately $5-8 \%$ of the population (USA) (2). Examples of these diseases are: type 1 diabetes, rheumatoid arthritis, and systemic lupus (3), with symptoms ranging in severity from fatigue, joint pain, seizures, skin rashes and others that might be related to vital organ damage (2). For those affected, rather than protecting them from disease, their immune system works against them. Their best chance of preventing irrecoverable organ damage is early detection and treatment.

The BIO-FLASH ${ }^{\circledR}$ was first released in 2009, with revisions prompting the 2012 BIO-FLASH ${ }^{\circledR} 2.4 .0$ (4). Dr. Fritzler explained that the BIO-FLASH ${ }^{\circledR}$ system uses chemiluminescence to detect the self-destructing immune molecules such as autoantibodies in the blood. More importantly, BIO-FLASH ${ }^{\circledR}$ identifies the precise products of the cell (specific proteins, nucleic acids, phospholipids) that the immune system is attacking, enabling the physician to make an accurate diagnosis-promoting early and accurate treatment. Hence, the BIO-FLASH ${ }^{\circledR}$ expedites the most appropriate and effective treatment, eliminating a manual trial and error (5) and subjective approach (6).

Dr. Fritzler stated, "The BIO-FLASH ${ }^{\circledR}$ detects certain abnormalities in blood when other systems fail." He also explained that the turn-around time to complete a BIO$\mathrm{FLASH}^{\circledR}$ test and generate a report has dramatically improved. Many tests can be completed in an hour, compared to past systems, which took up to a week. In addition, test reliability

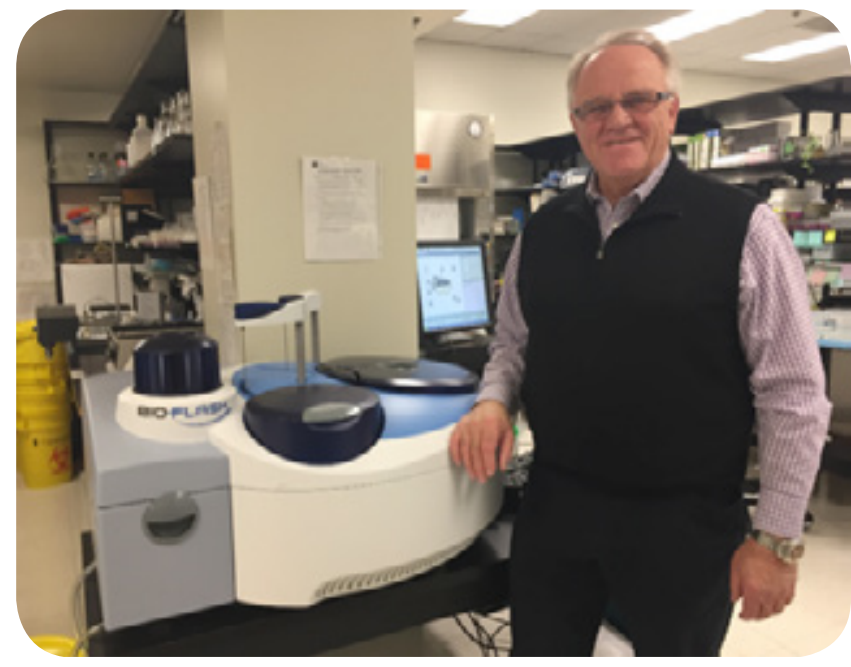

has improved substantially.

The BIO-FLASH ${ }^{\circledR}$ can process as many as 1,000 blood samples in a day (7). Recently, the University of Calgary adopted a second BIO-FLASH ${ }^{\circledR}$ system. Dr. Fritzler explained that one system is dedicated for patient services and tested approximately 50,000 blood samples last year. Of those samples, approximately $70 \%$ were from Albertans, $20 \%$ from other provinces, and $10 \%$ from other parts of the world such as Europe, Japan, Australia, and the USA.

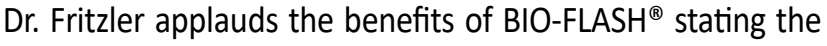
machine provides superior speed and reliability. "Faster results means the patient can be diagnosed and treated sooner. It has improved the work flow in our lab because it is fully automated and the results are incorporated in our Laboratory Information Systems and uploaded digitally to the patient's electronic health record on NetCare." And while new technology will encounter glitches, Dr. Fritzler stated that BIO-FLASH ${ }^{\circledR}$ has provided "excellent hands on technical support."

The second $\mathrm{BIO}-\mathrm{FLASH}^{\circledR}$ system is being used to develop new tests. Dr. Fritzler spoke passionately about his almost 40 years working at the University of Calgary, with a focus to improve the diagnosis of complex autoimmune diseases. Dr. Fritzler emphasized the necessity of early diagnosis, treatment, and disease prevention providing two examples. 


\section{HealTh SCIENCE INQUiRY}

The first example is that of an undiagnosed client with lupus, presenting for the first time to a physician and already showing signs of kidney disease. The second example pertains to a child, brought to the emergency room due to progressive seizures, reason unknown. Dr. Fritzler explained that if the cause is autoimmune encephalitis, an immediate life saving diagnosis can now be made with antibody testing. These two examples also illustrate Dr. Fritzler's ongoing research, to provide 'point of care' diagnostics that could be used in emergency rooms or at the patients' bedside to make diagnoses even faster. His lab is constantly evaluating leading edge technologies that can be used for personalized and preventative medicine.

For the University of Calgary, BIO-FLASH ${ }^{\circledR}$ epitomizes its desire and commitment to lead in research, detection, and prevention. For those who suffer from autoimmune diseases, such commitment to early detection and personalized medicine is highly welcomed.

\section{References}

1. Medline Plus [Internet]. Bethesda, MD: US National Library of Medicine; n.d. [updated 2013 July 16]. Available from: https://www.nlm.nih.gov/ medlineplus/ency/article/000816.htm

2. Pink R, Simek J, Vondrakova J, Faber E, Michl P, Pazdera J, et al. Saliva as a diagnostic medium. Biomed Pap Med Fac Univ Palacky Olomouc Czech Repub. 2009: 153(2):103-110.

3. Laborde A. World Health Organization [Internet]. Uruguay: World Health Organization, n.d. [updated 2011 October]. Available from: http://www. who.int/ceh/capacity/immune_diseases.pdf

4. BIO-FLASH ${ }^{\circledR}$ Operator's Manual. Barcelona, Spain; 2012. Available from: http://www.inovadx.com/portal/Technical\%20Support/BIOFLASH/ BioFlash_Operator_Manual.pdf

5. UCalgary Medicine [Internet]. Calgary: University of Calgary Cumming School of Medicine; 2015 [cited 2015 Nov 20]. Available from: http://issuu. com/ucalgarymedicine/docs/ucalgarymedicine_ss2015

6. Mahler M, Meroni P-L, Bossuyt X, Fritzler MJ. Current concepts and future directions for the assessment of autoantibodies to cellular antigens referred to as anti-nuclear antibodies. J Immunol Res. 2014; 1-18

7. Cyperling M. New machine could help diagnose autoimmune diseases earlier. UToday [Internet]. 2012 Sept [cited 2015 Nov 20]. [1 pp.] Available from: http://www.ucalgary.ca/news/utoday/september10-2012/bioflash 